\title{
Environmental Pollution Nexus Economic Growth and Energy Consumption
}

\author{
Michel Mivumbi, Xiaoling Yuan \\ School of Economics and Finance, Xi'an Jiaotong University, Xi'an, China \\ Email:michel@stu.xjtu.edu.cn, xiaoling@xjtu.edu.cn
}

How to cite this paper: Mivumbi, M., \& Yuan, X. L. (2021). Environmental Pollution Nexus Economic Growth and Energy Consumption. Modern Economy, 12, 677-688. https://doi.org/10.4236/me.2021.124034

Received: March 10, 2021

Accepted: March 28, 2021

Published: March 31, 2021

Copyright (C 2021 by author(s) and Scientific Research Publishing Inc. This work is licensed under the Creative Commons Attribution International License (CC BY 4.0).

http://creativecommons.org/licenses/by/4.0/

\begin{abstract}
This paper tests relationship between Rwanda's environmental pollution, human capital, physical capital, economic growth and energy consumption as Solow model function in period of 1990 and 2018. Paper used Johansen co-integration test method to estimate the long-run coefficients with the constant level relationship of variables and VAR for short-run coefficients. Verification of long runs co-integration equilibrium Rwanda's air pollution was found to depend on energy consumption significantly and economic growth insignificantly with positive coefficient and, slightly incline $\mathrm{CO}_{2}$ emission pollution. One percent increase to physical capital and human capital with negative coefficients and significance decline $\mathrm{CO}_{2}$ emission pollution. VAR implies that human capital affects Rwanda's air pollution for short-term. Rwandan's government should promote policies on new technology in economic development and, the managing method of human capital, physical capital and energy consumption to reduce $\mathrm{CO}_{2}$ emission that can adopted by government's sustainable environmental protection.
\end{abstract}

\section{Keywords}

Johansen Test, VAR, Air Pollution, Energy Consumption, Economic Growth

\section{Introduction}

Carbon dioxide and nitrogen dioxide are major pollutants in Rwanda, but in Kigali and other urban areas, air pollution is caused by vehicle emissions and industries, while poor air quality in residential and rural areas is caused by domestic wood, field burning and charcoal stoves. In 2014, Rwanda's carbon dioxide equivalents were 7.59 million tons. In Rwanda, most of the gas emissions of carbon dioxide with $87 \%$ mainly come from transportation with $52 \%$ and industrial processes with $28.5 \%$. Land use changes in forests and grasslands make 
Rwanda a net carbon sink. In 2005, the total carbon dioxide equivalent was dominated by agriculture and energy (Bernis et al., 2009).

In 2018, Rwanda's per capita carbon dioxide emissions were 0.09 metric tons, and have increased by $2.88 \%$ over the previous year and 39,234 tons from 2015. Based on the population in 2016, per capita carbon dioxide emissions are equivalent to 0.12 tons per person. $\mathrm{CO}_{2}$ emissions average GDP value was 42.79 percent from 1965 to 2017 (World Bank, 2011). In addition, even with investment, Rwanda's per capita carbon dioxide consumption may be much lower than the international average (Ministry of Trade and Industry, 2013). This paper aimed at analysing the relationship between environmental pollution, economic growth and energy consumption, not only for the interest of Rwanda, but also Sub-Sahara developing countries in purpose of knowing how air pollution of $\mathrm{CO}_{2}$ emission is emitted. Long-run relationship coefficients analysis was performed by estimating Johansen co-integration test and VAR for short run relationship, over a longer time span from 1990 to 2018. The paper proceeds in the following research structure sections. Section one states introduction of the study. Section two provides literature review of relationship of environmental pollution on economic growth and energy consumption. Section three describes the methodology within econometric framework for testing long-run co-integrations relationship and VAR model, while Section four presents the results data of empirical analysis; Section five summarizes and concludes; Section six is policies and recommendation.

\section{Literature Review}

Using panel co-integration, author Pao \& Tsai (2011) found that in long-term equilibrium, carbon dioxide emissions appear to be elastic for energy consumption and follow hypothesis of environmental Kuznets curve. The results show a robust two-way causal relationship between emissions and endogenous variables, and a robust one-way causal relationship between output and endogenous variables. The evidence seems to support pollution shelters and halo and scale effects.

Zhang \& Cheng (2009) research shows that in the long run, there is a one-way Granger causality between GDP and energy consumption, and there is a one-way Granger causality between energy consumption and carbon emissions; there is evidence that whether it is carbon emissions or energy consumption will not lead to economic growth. Ang (2007) believes that there is a strong correlation between pollutant emissions, energy consumption and output variables; the long-term impact of economic growth on energy use growth and pollution growth is causal, and from energy use growth to short-term Output growth is a unidirectional cause and effect relationship. Researcher Ozturk \& Acaravci (2010) pointed out that energy conservation policies, such as energy consumption quantification and the control of carbon dioxide emissions, may not adversely affect Turkey's actual output growth. The research by Tang, Tan, \& Ozturk 
(2016) found that energy consumption, foreign direct investment and capital stock have a positive impact on Vietnam's economic growth. The Granger causality test revealed a unidirectional causality from energy consumption to economic growth. Esso \& Keho (2016) believes that in the long run, energy consumption and economic growth are associated with increased air pollution (carbon dioxide emissions) in sub-Saharan African countries.

Lan, Kakinaka, \& Huang (2012) shows that pollution emissions is negatively correlated with higher levels of human capital and positively correlated with lower levels. The author Sapkota \& Bastola (2017) reveals that human capital has different effects on the pollution emissions of the Latin America.

However, Nair-Reichert \& Weinhold (2001) argues that while economic growth is deteriorating environmental resources, the increase in investment or the increase in its efficiency level effects on medium and long-term economic growth. Grossman \& Helpman (2011) emphasizes that increased competition and innovation lead to increased productivity and technological progress, thereby promoting economic developing in long run.

Researcher Apergis \& Payne (2010) pointed out from the error correction model that in the short and long term, there is a two-way causal relationship between economic growth and renewable energy consumption, and found a interdependence supports of hypothesis feedback. Xepapadeas (2005) found that the environmental Kuznets curve is related to ecological eminence and, the decomposition of total factor productivity is not only expected output, but also environmental pollution in economic production.

\section{Methodologies}

\subsection{Theoretical Model}

The Model starts by the following simplified Cobb-Douglas equation of the production function Solow (1956):

$$
P=A K^{\alpha} L^{\beta} Y^{\phi}
$$

where $P$ denotes amount of output environment pollution produced. $K, L$ and $Y$ are the amount of capital, labor force and GDP in the economy. $A$ is a productivity factor that represents energy consumption $E$ to increase the output. Elasticity of capital, labor and GDP are $\alpha, \beta$ and $\phi$ respectively. In the neoclassical model A represents the exogenous state of technology (energy consumption); and it increase output without changing the inputs of labor, capital and GDP. In the endogenous growth models, technological change is driven by an interaction of factors within the economy. Formula (2) notes that the sum of the natural logarithms is equal to the natural logarithm of the product, Equation (1) become:

$$
\ln P=\ln E+\alpha \ln K+\beta \ln L+\phi \ln Y
$$

Endogenous growth theory is the product of describing economic growth as a feature of economic structure. Environmental pollution is seen as affecting 
long-term economic growth through new technologies, gross fixed capital and energy consumption. Differential with respect time Equation (2) produce:

$$
\mathrm{d} P / P=\mathrm{d} E / E+\alpha \mathrm{d} K / K+\beta \mathrm{d} L / L+\phi \mathrm{d} Y / Y
$$

Because the relationship is multiplicative in the variables, the econometric model linearizes by converting it to a difference instead of differential due to short time. Equation (3) becomes:

$$
\Delta P / P=\Delta E / E+\alpha \Delta K / K+\beta \Delta L / L+\phi \Delta Y / Y
$$

Then, taking the time derivative of Equation (3), we get Equation (5) as follows:

$$
g_{P}=g_{E}+\alpha g_{K}+\beta g_{L}+\phi g_{Y}
$$

where, $\alpha, \beta, \phi, \gamma$ are the elasticities of output respectively to $K, L, Y, E$; and $g$ is constant growth rate with its corresponding variables. The output growth rate in Equation (5) represents the linear sum of the total factor production (energy consumption) rate, the input capital growth rate, the input labor growth rate, and the input GDP growth rate. Output growth rate from various inputs contribution were $\alpha g_{k} / g_{p}, \beta g_{L} / g_{p}, \phi g_{y} / g_{p}$. Energy consumption to environmental pollution was:

$$
g_{E} / g_{p}=1-\alpha g_{k} / g_{p}-\beta g_{L} / g_{p}-\phi g_{y} / g_{p}
$$

\subsection{Data Sources Description}

The study used data from World Bank country data, OECD country data sources and the International Monetary Fund, and the time of the data was 10/28/2019. GDP growth (annual percentage) rate used as a proxy of macroeconomic performance, Table 1 below describe variables used.

Table 1. Description variables.

\begin{tabular}{cccccc}
\hline & LNE & LNGDP & LNK & LNL & LNP \\
\hline Mean & 4.486 & 2.111 & 2.826 & 15.268 & -2.626 \\
Median & 4.490 & 2.125 & 2.719 & 15.296 & -2.642 \\
Maximum & 4.512 & 3.562 & 3.236 & 15.571 & -1.852 \\
Minimum & 4.401 & 0.789 & 2.533 & 14.897 & -3.147 \\
Std. Dev. & 0.025 & 0.531 & 0.259 & 0.210 & 0.449 \\
Skewness & -1.736 & 0.196 & 0.456 & -0.354 & 0.219 \\
Kurtosis & 6.738 & 5.249 & 1.538 & 1.960 & 1.581 \\
Jarque-Bera & 22.778 & 4.563 & 2.596 & 1.385 & 1.930 \\
Probability & 0.000 & 0.102 & 0.273 & 0.500 & 0.381 \\
Sum & 94.202 & 44.327 & 59.334 & 320.627 & -55.135 \\
Sum Sq. Dev. & 0.013 & 5.640 & 1.337 & 0.885 & 4.026 \\
Observations & 21 & 21 & 21 & 21 & 21 \\
\hline
\end{tabular}


In this study, the GDP growth rate at that time $t$ was used as the natural logarithm $Y_{t}=L N G D P_{t}$. Rodríguez-Pose \& Tselios (2010) found that the current level of inequality and the income and education in a region were set. The increase in equality is significantly positively related to subsequent economic growth.

While physical capital $K_{t}=L N K_{t}$ is variable of gross fixed capital percentage of GDP at time $t$ as natural logarithm. It represents all the investment in that economy in the given year. Decomposition of capital formation into private and public investments facilitates the identification of pollution and energy consumption to fix the source.

Natural logarithm of total labor force represented by $L_{t}=L N L_{t}$ it includes total people who are employed; as persons whose age were engaged in any activity of producing goods or else any activity of providing services for pay or profit in an economy during a specified period (World Bank, 2018).

Natural logarithm of environmental pollution is represented by $P_{t}=\ln P_{t}$ it includes carbon dioxide emissions that are stemming from the burning of fossil fuels.

Natural logarithm of renewable energy in total final energy consumption is represented by $E_{t}=\ln E_{t}$. World Bank and Sustainable energy for all are the most source organization data.

\section{Empirical Analysis}

\subsection{Unit Root Test}

The use of ordinary least squares OLS relies on a stationary random process. To estimate the slope coefficient, first perform a unit root test for stationarity testing. Eview9 version will be the econometric software package to be used.

Table 2 describes the ADF test when the variable is tested for the unit root with a trend term within an intercept. The results show that all variables at this level are non-stationary. Therefore, the null hypothesis of non-stationary variables is not denied. Again, because when the test was performed on the first difference, all variables became stable at the $5 \%$ significance level. This conclusion is based on the comparison of statistical tests and tabulated critical values, that is, when I(1) order integration, the variables are non-stationary. Therefore, null hypothesis reject non-stationary. When ADF is performed on the variables, including the intercept and trend terms, the results are slightly different. As shown in Table 2, non-stationary null hypothesis tests will be rejected. Now, after realizing that all considered variables are non-stationary (with unit root) at their level, but after their first difference becomes stationary (no unit root), the long-term equilibrium relationship in Co-integration is performed in the modeling method.

\subsection{Co-Integration Test}

The empirical analysis of co-integration of economic growth is based on the 
natural logarithm of pollution ( $\mathrm{LnP})$ as the dependent variable, and natural logarithm of gross fixed capital formation ( $\mathrm{LnK}$ ) natural logarithm of total employment (LnL), natural logarithm of Energy consumption (LnE) and natural logarithm of GDP (LnGDP). Analysis is using Johansen eigenvalue test co-integration methods where 3 are chosen as optimal lag order. In this modeling the coefficients of the co-integration vector are interpreted as long-term elasticity and, the first difference is interpreted as the pollution rate. Null hypothesis there is no co-integration equation while the alternative hypothesis $\mathrm{Ho}$ is not true (Table 3 ).

\subsection{Regression Analysis}

Figure 1 shows the trends of variables used in the study and describes features of data. It provides summaries for sample and measures. In particular variables are in first difference: $\mathrm{D}(\mathrm{LNE}), \mathrm{D}(\mathrm{LNGDP}), \mathrm{D}(\mathrm{LNK}), \mathrm{D}(\mathrm{LNL})$, and $\mathrm{D}(\mathrm{LNP})$. The results from this analysis indicate that it has been stable over the period, but nonetheless the trends show that labor becomes stable after some of the period of time. This implies that the labor as a result has been, on an incline rate in an economy leads to an increase in the standard of living as well.

Table 2. ADF Unit Root Test results with intercept and trend.

\begin{tabular}{cccc}
\hline Variables name & Kind of test $(\mathrm{C}, \mathrm{T}, \mathrm{K})$ & ADF test value & Comment \\
\hline LNGDP/ D(LNGDP) & $(\mathrm{C}, \mathrm{T}, 2) /(\mathrm{C}, \mathrm{T}, 2)$ & $-4.25 /-4.64^{* *}$ & Non-Stationary/Stationary \\
LNK/ D(LNK) & $(\mathrm{C}, \mathrm{T}, 0) /(\mathrm{C}, \mathrm{T}, 0)$ & $-2.70 /-6.74^{* * *}$ & Non-Stationary/Stationary \\
LNL/ D(LNL) & $(\mathrm{C}, \mathrm{T}, 6) /(\mathrm{C}, \mathrm{T}, 1)$ & $-10.73 /-10.76^{* *}$ & Non-Stationary/Stationary \\
LNP/ D(LNP) & $(\mathrm{C}, \mathrm{T}, 0) /(\mathrm{C}, \mathrm{T}, 0)$ & $-2.47 /-5.18^{* *}$ & Non-Stationary/Stationary \\
LNE/D(LNE) & $(\mathrm{C}, \mathrm{T}, 5) /(\mathrm{C}, \mathrm{T}, 4)$ & $0.24 /-7.31^{* *}$ & Non-Stationary/Stationary \\
\hline
\end{tabular}

Notes: (1) D represents the first-order difference of the variables; (2) Test type (C, T, K), where C and T represent the intercept and trend in the test equation, and K represents the AIC lag length; (3) ***,**, * represent significance levels at $1 \%, 5 \%, 10 \%$ respectively.

Table 3. Co-integration equation relationship.

\begin{tabular}{ccccc}
\hline \multicolumn{5}{c}{ Unrestricted Cointegration Rank Test (Trace) } \\
\hline Hypothesized & & Trace & 0.05 & \\
\hline No. of CE(s) & Eigenvalue & Statistic & Critical Value & Prob. $^{* *}$ \\
\hline None & 0.993 & 143.290 & 69.819 & 0.0000 \\
At most 1 & 0.664 & 54.827 & 47.856 & 0.0008 \\
At most 2* & 0.578 & 35.197 & 29.797 & 0.0098 \\
At most 3* & 0.522 & 19.659 & 15.494 & 0.0339 \\
At most 4 & 0.298 & 6.358 & 3.842 & 0.0461 \\
\hline
\end{tabular}

Trace test indicates 5 cointegrating equation(s) at the 0.05 level; ${ }^{*}$ denotes rejection of the hypothesis at the 0.05 level; ${ }^{* *}$ p-values. 

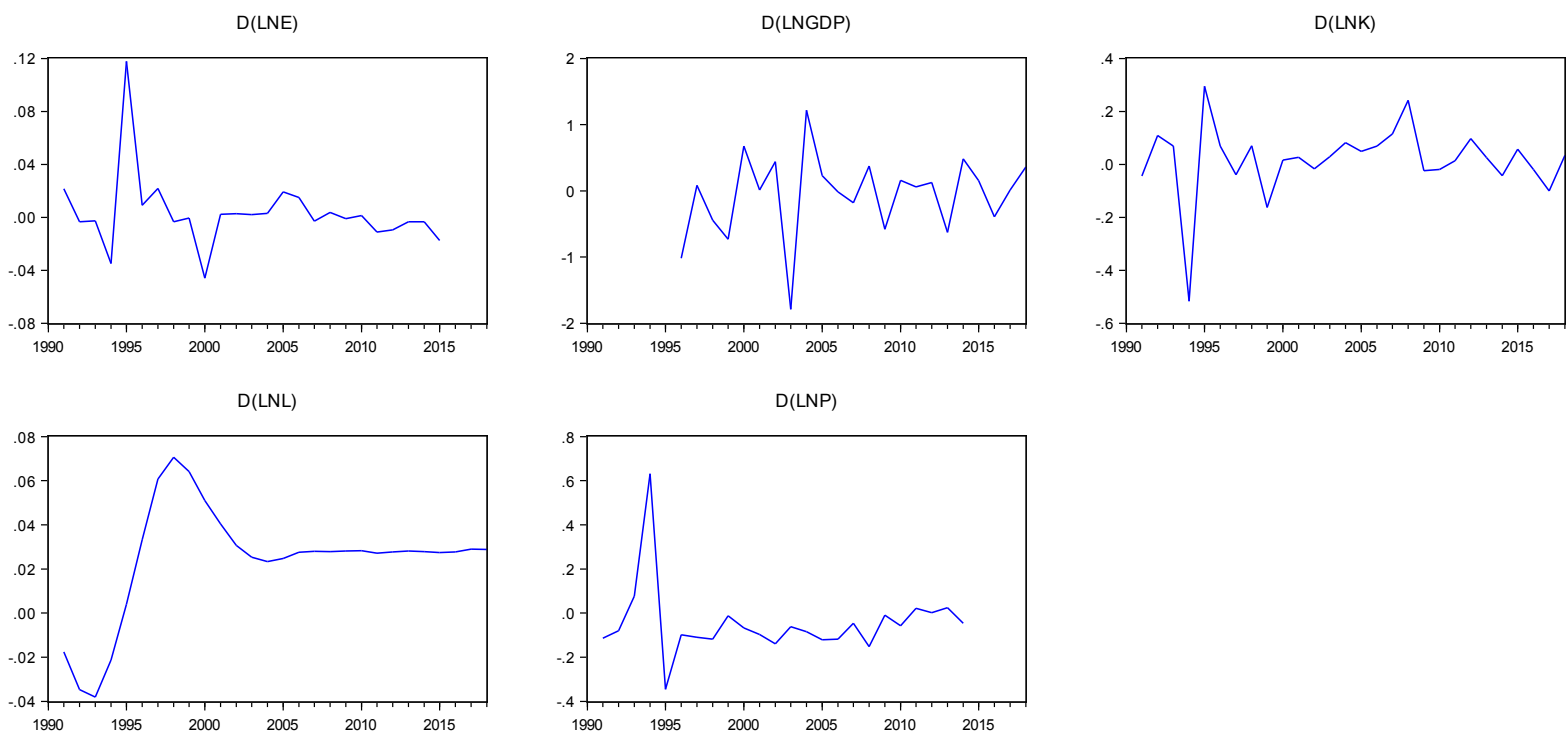

Figure 1. Trend analysis.

To examine changes in the regression coefficients analysis, step by step regression method was utilized. Result analysis regressions are in Table 4 to describe features of data. By regression processing economic growth are linearly not significant, where increase $1 \%$ of economic growth inclines $2.4 \%$ of $\mathrm{CO}_{2}$ pollution. Coefficient of energy consumption is positive and statistically significant at 5\% level, one percent increase of energy consumption increase $40.6 \%$ of $\mathrm{CO}_{2}$ pollution. Changes in economic growth and energy consumption reflect the matching of dominant $\mathrm{CO}_{2}$ emission. Where elasticities output of physical capital and human capital are negative but significant at 5\% levels, which have become a booster for Rwanda's $\mathrm{CO}_{2}$ pollution emissions. The reason is that the deviation of physical capital and human capital from optimization will have a negative impact on $\mathrm{CO}_{2}$ pollution emission. However, economic growth and energy consumption have brought negative and positive benefits to physical capital and human capital.

From the DW value, the model regression residuals have strong autocorrelation. White test for heteroskedasticity in Table 5 reject null hypothesis where all variance are the same. In addition, the explanatory variables $\mathrm{K}, \mathrm{L}, \mathrm{Y}$, and $\mathrm{E}$ have different effects on $\mathrm{CO}_{2}$ pollution emission and may be affected environmentally. Endogenous problems can also cause this effect.

\subsection{VAR Model}

According to the AIC criterion of the minimum criterion, the VAR (3) model is established. After testing, the model is significant, and the reciprocal of the characteristic root mode is less than 1, indicating that the VAR model structure is stable, where impulse response function plus variance decomposition are measured. Empirical analysis of the impulse response function is used to measure the trajectory of the random deviation \& standard deviation on other current 
and future variables. It can directly describe the dynamic interaction and influence between variables. Horizontal line symbolizes review period; vertical line symbolizes response of the dependent single variable. Solid line indicates response function curve, and dashed line indicates double standard deviation confidence interval (Figure 2).

Table 4. Regression Results under LNP as dependent variable.

\begin{tabular}{ccccc}
\hline \multicolumn{5}{c}{ Dependent Variable: LNP } \\
\hline Variable & Coefficient & Std. Error & t-Statistic & Prob. \\
\hline LNE & 4.068 & 0.914 & 4.453 & 0.0003 \\
LNGDP & 0.024 & 0.079 & 0.305 & 0.7643 \\
LNK & -0.763 & 0.211 & -3.622 & 0.0021 \\
LNL & -1.229 & 0.290 & -4.239 & 0.0006 \\
R-squared & 0.891006 & Mean dependent var & -2.625489 \\
Adjusted R-squared & 0.871772 & S.D. dependent var & 0.448666 \\
S.E. of regression & 0.160663 & Akaike info criterion & -0.649375 \\
Sum squared resid & 0.438813 & Schwarz criterion & -0.450419 \\
Log likelihood & 10.81844 & Hannan-Quinn criter. & -0.606196 \\
Durbin-Watson stat & 0.404249 & & \\
\hline
\end{tabular}

Table 5. White heteroskedasticity test.

\begin{tabular}{cccc}
\hline F-statistic & 2.006 & Prob. F(12, 8) & 0.1421 \\
\hline Obs $^{*}$ R-squared & 7.0148 & Prob. Chi-Square(12) & 0.1351 \\
Scaled explained SS & 3.2909 & Prob. Chi-Square(12) & 0.5104 \\
\hline
\end{tabular}

Response to Cholesky One S.D. Innovations \pm 2 S.E.

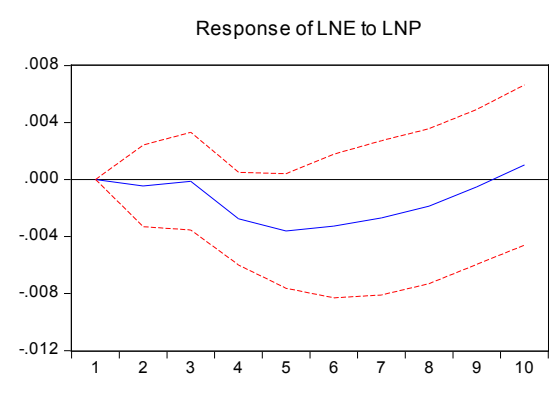

Response of LNGDP to LNP
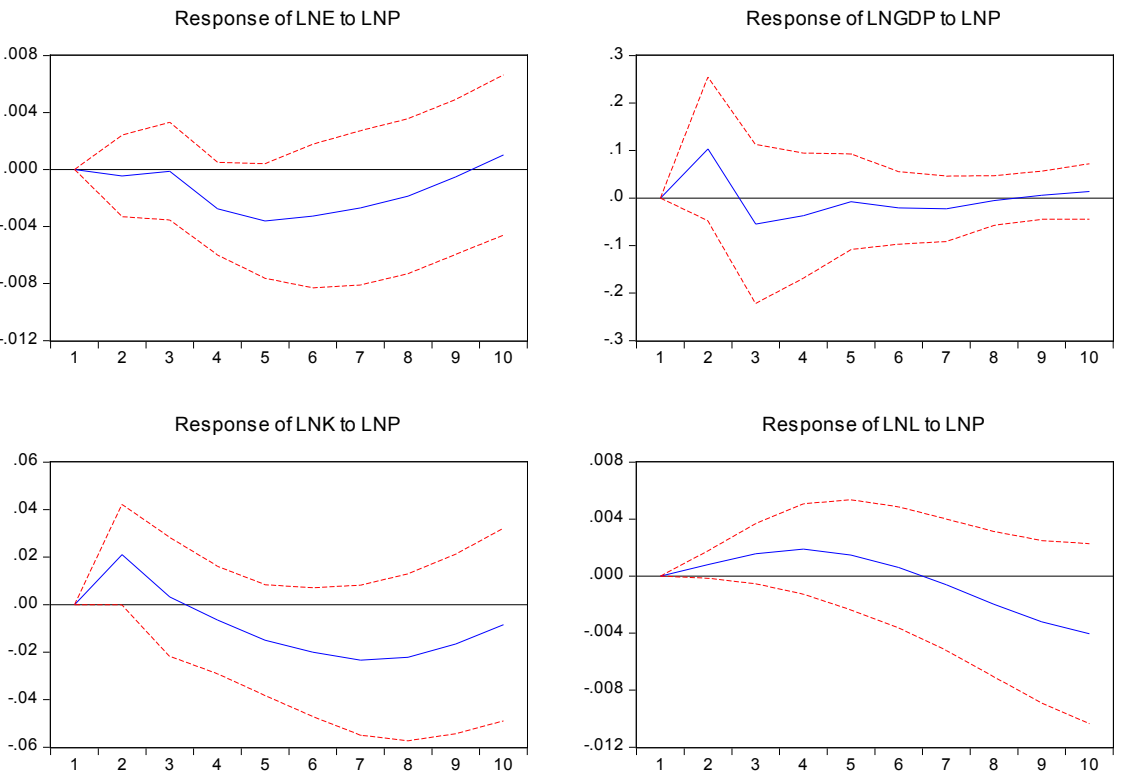

Figure 2. Influence of different variation on environmental pollution. 
1) The response to LnGDP reflects the impulse response function of environmental pollution to the GDP's standard deviation. When promoting (impulsing) GDP during this period, the first two periods had positive effects, and the third period gradually decreased to the maximum negative steady-state point. Then there is a positive reaction; in the sixth stage, it drops sharply to the minimum negative point, and then in the ninth stage, fast convergence obtained and again becomes positive reaction. The data shows that with economic growth, the intensity of environmental pollution in the first two periods will increase, and then the intensity of environmental pollution will decrease, showing volatility. But the scope of the volatility has narrowed, and the time is increasing. 2) The response of environmental pollution to gross fixed capital formation reflects the impulse response function of the standard deviation of environmental pollution. It can be seen that the response of environmental pollution to physical capital is increasing to in the second period, the negative fell to the lowest in the third period, followed by the corresponding positive reaction, and it quickly converged after the sixth period. The results show that with the increase of gross fixed capital formation, the environmental pollution in the third periods will decrease, and its impact on environmental pollution shows volatility over time, but the amplitude of fluctuations is getting smaller and smaller, and the fluctuation time is getting longer. 3) The response of $\ln E$ reflects the response of the standard deviation of the new benefits of environmental pollution to energy consumption. From this period, it can be seen that the standard deviation increases to the third period and decreases negatively to the fourth period. To the steady state, rapid convergence occurs after the fourth cycle. 4) Under the active labor impulse of a unit, environmental pollution has not changed in the second and third stages. The second stage is a positive change, the change reaches the maximum. The response gradually decreases from the third stage to the eighth stage, reaches a negative maximum value from the eighth stage to the ninth stage, and then tends to converge. Labor will stimulate environmental pollution and promote pollution changes, this effect is short-term.

Table 6. Variance decomposition of LNP.

\begin{tabular}{ccccccc}
\hline Period & S.E. & LNE & LNGDP & LNK & LNL & LNP \\
\hline 1 & 0.0097 & 17.9664 & 24.4168 & 12.5384 & 38.2282 & 6.8502 \\
2 & 0.0120 & 21.9006 & 29.2054 & 11.1079 & 32.2161 & 5.5700 \\
3 & 0.0128 & 19.9122 & 28.0336 & 8.5272 & 37.5478 & 5.9793 \\
4 & 0.0165 & 18.4659 & 22.7568 & 7.1288 & 44.6678 & 6.9805 \\
5 & 0.0203 & 17.2302 & 18.4998 & 6.4542 & 49.7925 & 8.0234 \\
6 & 0.0224 & 15.8287 & 16.1517 & 6.4562 & 52.7582 & 8.8052 \\
7 & 0.0238 & 14.9013 & 15.0024 & 6.7229 & 54.0495 & 9.3239 \\
8 & 0.0245 & 14.5828 & 14.8682 & 6.8459 & 54.1377 & 9.5654 \\
9 & 0.0248 & 14.5543 & 15.3143 & 6.8002 & 53.7981 & 9.5331 \\
10 & 0.0255 & 14.3928 & 15.4790 & 6.8807 & 53.9131 & 9.3345 \\
\hline
\end{tabular}


It can be seen from Table 6 that since the VAR model at the beginning of the period, energy consumption, economic growth and physical capital have a greater impact on environmental pollution changes, reaching $17.9 \%, 24.4 \%$ and $12.5 \%$; and the impact is steadily decreased with the time. The human capital contribute little to the environmental pollution change at the beginning, but their ability to explain the macroeconomic growth change increases with the going of time. In stable state, human capital change contributions of environmental pollution is increasing and reach $53.9 \%$.

\section{Summary and Conclusion}

The overall goal of the study is to make an empirical analysis of the dynamic relationships between air pollution, Rwanda's GDP growth rate, gross fixed capital, labor, and energy consumption from 1990 to 2018. Air pollution was the dependent variable as an indicator of $\mathrm{CO}_{2}$ emission. GDP growth, labor, gross fixed capital formation, and energy consumption were independent variables. Based on the "boundary" test results, a study showed that dependent variable is actually co-integrated with other independent variables. The current research uses the Johansen co-integration test for long-run and VAR for short-run. Physical capital and human capital are expected to decrease air pollution for long-run; while growth rate of GDP and energy consumptions will increase air pollution as well. Although many empirical studies have assumed that GDP growth and energy consumption will affect air pollution. For short run energy consumption, economic growth and physical capital have a great impact on environmental pollution which steadily deceased with the time. Eviews9 is the software used in this study. A study showed that LnP is actually co-integrated with other independent variables. The findings from the study indicate that energy consumption and economic growth are significantly influencing air pollution in a long-term dynamic.

\section{Policy and Recommendations}

The Rwandan government should promote new technology policies for factory industries that promote investment such as macroeconomic stability to encourage foreign investors and domestic investment as engines of economic development from energy consumption. This is because energy consumption variables have an effective/influence on GDP growth rate. However, the challenge of providing new technology of gas emission from vehicle and industries must be overcome for environmental sustainability. In a way to create competitive advantage and benefit from spillover effect and Rwanda should have absorptive capability of advanced technology of environmental protections to fully have sustainable environmental. The limitation policy must ensure the entire environmental benefits.

\section{Conflicts of Interest}

The authors declare no conflicts of interest regarding the publication of this paper. 


\section{References}

Ang, J. B. (2007). $\mathrm{CO}_{2}$ Emissions, Energy Consumption, and Output in France. Energy Policy, 35, 4772-4778. https://doi.org/10.1016/j.enpol.2007.03.032

Apergis, N., \& Payne, J. E. (2010). Renewable Energy Consumption and Growth in Eurasia. Energy Economics, 32, 1392-1397. https://doi.org/10.1016/j.eneco.2010.06.001

Bernis, B., Carey, C., Cole, M., Dyszynski, J., \& Warnest, M. (2009). National Strategy on Climate Change and Low Carbon Development for Rwanda Baseline Report. Yoga Journal, No. 219, 35-42.

Esso, L. J., \& Keho, Y. (2016). Energy Consumption, Economic Growth and Carbon Emissions: Cointegration and Causality Evidence from Selected African Countries. Energy, 114, 492-497. https://doi.org/10.1016/j.energy.2016.08.010

Grossman, G. M., \& Helpman, E. (2011). Endogenous Innovation in the Theory of Growth. Journal of Economic Perspectives, 8, 23-44.

Lan, J., Kakinaka, M., \& Huang, X.G. (2012). Foreign Direct Investment, Human Capital and Environmental Pollution in China. Environmental and Resource Economics, 51, 255-275.

Ministry of Trade and Industry (2013). Rwanda Private Sector Development Strategy 2013-2018, Unleashing the Private Sector in Rwanda. MINICOM Website.

Nair-Reichert, U., \& Weinhold, D. (2001). Causality Tests for Cross-Country Panels: A New Look at FDI and Economic Growth in Developing Countries. Oxford Bulletin of Economics \& Statistics. https://doi.org/10.1111/1468-0084.00214

Ozturk, I., \& Acaravci, A. (2010). $\mathrm{CO}_{2}$ Emissions, Energy Consumption and Economic Growth in Turkey. Renewable and Sustainable Energy Reviews, 14, 3320-3225. https://doi.org/10.1016/j.rser.2010.07.005

Pao, H. T., \& Tsai, C. M. (2011). Multivariate Granger Causality between $\mathrm{CO}_{2}$ Emissions, Energy Consumption, FDI (Foreign Direct Investment) and GDP (Gross Domestic Product): Evidence from a Panel of BRIC (Brazil, Russian Federation, India, and China) Countries. Energy, 36, 685-693. https://doi.org/10.1016/j.energy.2010.09.041

Rodríguez-Pose, A., \& Tselios, V. (2010). Inequalities in Income and Education and Regional Economic Growth in Western Europe. Annals of Regional Science, 349, 375. https://doi.org/10.1007/s00168-008-0267-2

Sapkota, P., \& Bastola, U. (2017). Foreign Direct Investment, Income, and Environmental Pollution in Developing Countries: Panel Data Analysis of Latin America. Energy Economics, 64, 206-212. https://doi.org/10.1016/j.eneco.2017.04.001

Solow, R. M. (1956). A Contribution to the Theory of Economic Growth. The Quarterly Journal of Economics, 70, 65-94. https://doi.org/10.2307/1884513

Tang, C. F., Tan, B. W., \& Ozturk, I. (2016). Energy Consumption and Economic Growth in Vietnam. Renewable and Sustainable Energy Reviews, 54, 1506-1514.

https://doi.org/10.1016/j.rser.2015.10.083

World Bank (2011). World Development Report 2011: Conflict, Security, and Development (pp. 416). Washington DC: World Bank.

World Bank (2018). Employment in Agriculture (\% of Total Employment). World Development Indicators.

Xepapadeas, A. (2005). Chapter 23 Economic Growth and the Environment. In K.-G. Mäler, \& J. R. Vincent (Eds.), Handbook of Environmental Economics (Vol. 3, pp. 1219-1271). Amsterdam: Elsevier B.V. https://doi.org/10.1016/S1574-0099(05)03023-8 
Zhang, X. P., \& Cheng, X. M. (2009). Energy Consumption, Carbon Emissions, and Economic Growth in China. Ecological Economics, 68, 2706-2712.

https://doi.org/10.1016/j.ecolecon.2009.05.011 